\title{
Quality and Value of Nuclear Medicine and Molecular Imaging: The Impact of Health-Care Reform*
}

Kristi R. Mitchell ${ }^{1}$ and Susan K. Bunning ${ }^{2}$

${ }^{1}$ Avalere Health, LLC, Washington, District of Columbia; and ${ }^{2}$ Society of Nuclear Medicine and Molecular Imaging, Reston, Virginia

$\mathbf{O}$ the heels of one of the most contentious, divisive general elections in recent history, one topic will remain front and center: our nation's health care. Political pundits and prominent health-care experts concur that health-care reform is here to stay. As we enter into its third year of implementation, a salient question remains: What does health reform mean for nuclear medicine and molecular imaging? The objectives of this article are, first, to present a background of key provisions of the Affordable Care Act and its relevance to nuclear medicine and molecular imaging; second, to highlight specific challenges in defining and measuring quality in the field; and third, to outline future trends that will be anticipated in the coming year.

Inefficiencies in our health-care delivery system and market failures have fueled demands for change. Healthcare expenditures in the United States are currently about $18 \%$ of the gross domestic product and have been projected to rise sharply over the next several years (1). Despite these expenditures, the United States is lagging behind other industrial nations across multiple key indicators of quality (2), including 5-y survival rates for breast cancer and rates of lower-extremity amputations due to diabetes (3). These observations have led to the need for health reform. At the same time, in the era of governmental deficit reduction, employers facing rising health-care costs and an uncertain market have caused the cost of care to shift toward patients.

The health-care reform law enacted in March 2010 is known by many names: the Patient Protection and Affordable Care Act, the Affordable Care Act, or sometimes Obamacare. Because the first name, Patient Protection and Affordable Care Act, was considered too long, it was shortened to Affordable Care Act (ACA) when the law was amended. The ACA resulted in the most sweeping changes to health-care coverage, financing, organization, and delivery of services since the creation of Medicare and Medicaid programs during President

Received Nov. 13, 2012; revision accepted Jan. 23, 2013.

For correspondence or reprints contact: Susan K. Bunning, SNMMI, 1850

Samuel Morse Dr., Reston, VA 20190.

E-mail: sbunning@snmmi.org

*NOTE: FOR CE CREDIT, YOU CAN ACCESS THIS ACTIVITY THROUGH

THE SNMMI WEB SITE (http://www.snmmi.org/ce_online) THROUGH MARCH 2015.

COPYRIGHT (C) 2013 by the Society of Nuclear Medicine and Molecular Imaging, Inc.

DOI: $10.2967 /$ jnmt.112.117051
Johnson's Great Society, an era in the 1960s characterized by greater emphasis on public health. The cornerstone of current health reform is an emphasis on improving quality, efficiency, and patient experience through achieving 3 main goals: coverage and insurance market reform, financial strategies for health reform, and delivery and payment system reform.

Almost everyone recognizes the more famous portions of the ACA that focus on coverage and insurance market reform: the individual-insurance mandate, individuals up to $26 \mathrm{y}$ old qualifying for their parents' insurance coverage, the health-care exchanges, and the ban on annual and lifetime limits.

Although financial strategies are foundational to health reform, ACA has signaled incremental, not fundamental, changes to payment strategies by first seeking to demonstrate innovative payment models. Public and private payers are experimenting with a variety of payment reform approaches from bundled payments to global payments, integrating quality measurement and reporting into the payment system. Such financial reform models are highlighted in Table 1.

\section{DELIVERY AND PAYMENT REFORM}

The key to achieving the goals of the ACA will be the infrastructure for measures supporting quality improvement, efficiency, and payment and delivery reforms. What most people are not familiar with is the implementation of these elements, which directly and dramatically affects the practice of medicine.

In an attempt to place outcome measurement at the center of health reform, there has been a renewed effort to shift away from volume payment and toward value. No longer will physicians be rewarded solely for providing more care, but for providing high-quality care as defined by meeting and in some cases exceeding performance standards set by public and private payers. These recent efforts represent another way to rectify the inappropriate, perverse incentives wreaking havoc in our health-care system.

Transparency has risen as an important element that is required for reformation of the nation's health-care system. Presently, there is a tremendous lack of public information on cost and quality required to drive consumer behavior and promote competition. However, this lack of information is often predicated on the lack of a robust information highway to capture the most needed data to document high-quality care and to track and monitor the provision of care across multiple delivery settings. There are insufficient data on what works best, with treatment varying from community to community and pervasive safety and quality concerns. The infrastructure necessary to 
TABLE 1

A Variety of Payment Reform Approaches Emerges

\begin{tabular}{cccc}
\hline \multicolumn{1}{c}{ Bundled } & Episode & Condition & Global \\
\hline Payment for a tightly & Payment for all or most services & Payment for all or most services & Payment for all or most \\
linked set of services & delivered by related providers & delivered by related providers & services delivered by \\
provided by one or a & attendant to a time-delimited & attendant to a specified disease & related providers to a \\
small number of providers & "episode of care" (e.g., hip & or condition, such as asthma, & heterogeneous population \\
& replacement surgery and & over a specified time & (e.g., Medicare Advantage \\
& rehabilitation) & & program) \\
& & &
\end{tabular}

gather and share such information is only at the very beginning stages for imaging. However, as a result of the drive toward implementation of electronic medical records across our nation's hospitals and office-based practices, Centers for Disease Control and Protection data suggest that $54 \%$ of offices in particular have now adopted this technology, a definite step in the right direction toward reforming our health system (Fig. 1) (4).

To achieve the 3 goals, there are several ongoing initiatives designed to help perform the mission of the ACA, as described in the following sections.

\section{Center for Medicare and Medicaid Innovation}

The Center for Medicare and Medicaid Innovation fosters health-care transformation by finding new ways to pay for and deliver care that improves health while lowering costs. The center identifies, develops, supports, and evaluates innovative models of payment and care delivery for Medicare, Medicaid, and Children's Health Insurance
Program beneficiaries using an open, transparent, and competitive process. The center will also focus on all value-based purchasing. On its Web site, the Agency for Healthcare Research and Quality has defined value-based purchasing as the concept that "buyers should hold providers of health care accountable for both cost and quality of care. Valuebased purchasing brings together information on the quality of health care, including patient outcomes and health status, with data on the dollar outlays going toward health. It focuses on managing the use of the health care system to reduce inappropriate care and to identify and reward the best-performing providers. This strategy can be contrasted with more limited efforts to negotiate price discounts, which reduce costs but do little to ensure that quality of care is improved."

\section{Independent Payment Advisory Board}

Perhaps the most politically controversial addition under the ACA was the Independent Payment Advisory Board, which is

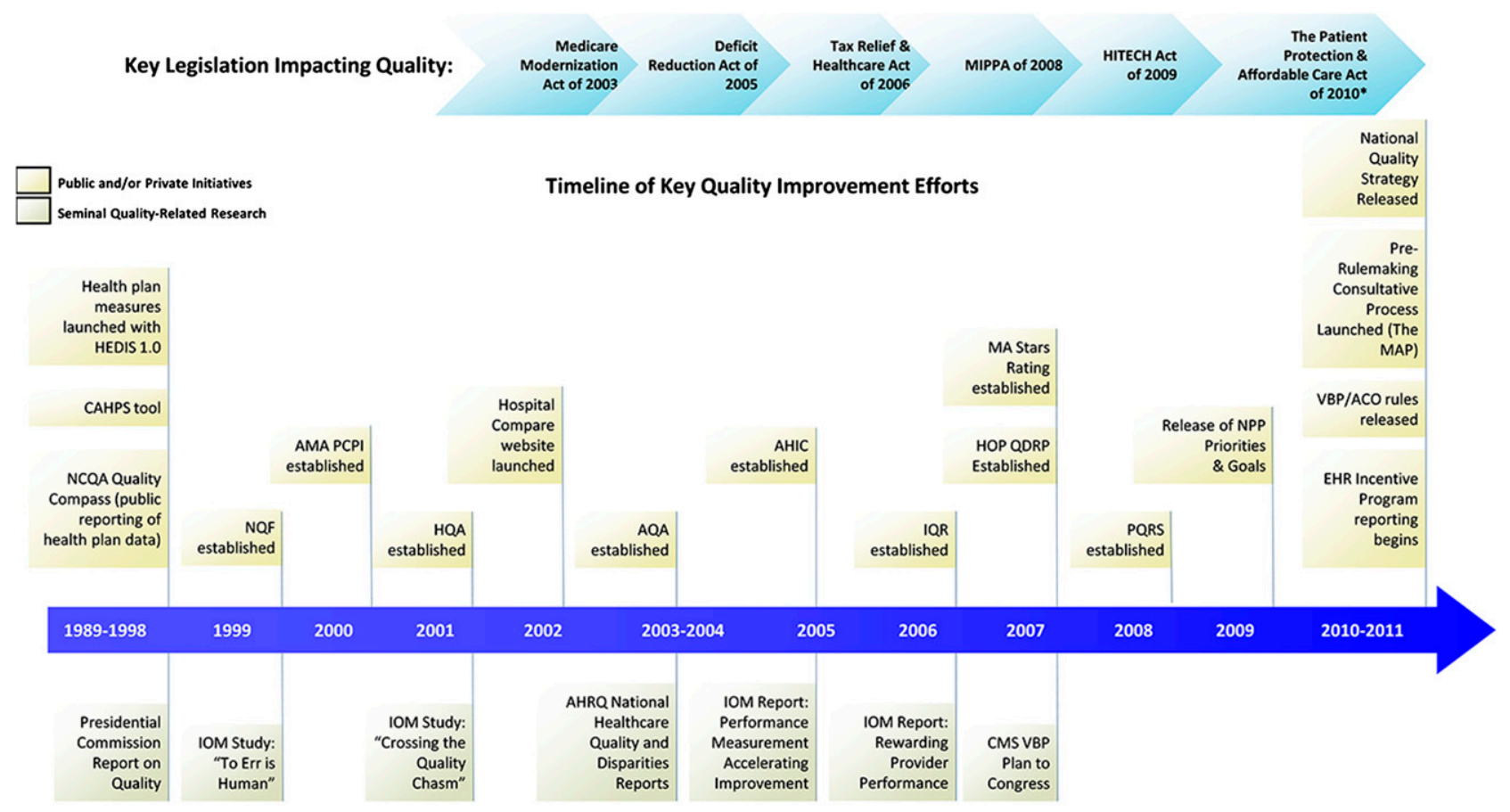

MIPPA: Medicare Improvements for Patients \& Providers Act HITECH: The Health Information Technology for Economic and Clinical Health PCPI: Physician Consortium for Performance Improvement HQA: Hospital Quality Alliance AQA: Ambulatory Quality Alliance AHIC: America's Health Information Community NPP: National Priorities Partnership MAP: Measure Applications Partnership EHR: Electronic Health Record MU: Meaningful Use VBP: Value-Based Purchasing ACO: Accountable Care Organization

- Therapeutic Specific Provisions Provided in Appendix E.

Source:

1. Corrigan, Janet. Overview presented at the National Pharmaceutical Council Town Hall Meeting ion Implications and Opportunities in Quality Measure Development and Use, Bridgewater, New Jersey, May 5, 2011. Modified by Avalere Health, UC on 11/7/2012

FIGURE 1. Timeline of key quality improvement efforts. 
a 15-member agency that has the task of achieving specified savings in Medicare without affecting coverage or quality. Previously, changes to Medicare payment rates and program rules were recommended by MedPAC but required an act of Congress to take effect. The new system grants the Independent Payment Advisory Board the authority to make changes to the Medicare program, with Congress being given the power to overrule the agency's decisions through a supermajority vote.

\section{Patient-Centered Outcomes Research Institute (PCORI)}

PCORI was created to fund comparative effectiveness research that will provide patients, their caregivers, and clinicians with the evidence-based research. According to the PCORI director, Dr. Joe Selby, "There was some thought that comparative effectiveness research, among other things, could identify wasteful therapies and decisions that were currently being made in the absence of evidence. Comparative effectiveness research was seen as a vehicle for getting more answers out there, more information at the disposal of decision-makers. PCORI funding was specified in the ACA through 2019. The funding is ramped up gradually. It was $\$ 10$ million in 2010, \$50 million in 2011, \$150 million this year, and each of those contributions comes directly from the Treasury. Each year going forward, the Treasury will contribute $\$ 150$ million to PCORI, but beginning in October 2013, an additional source of income will come from a $\$ 1$ fee levied on every insured person, whether [that person is] insured through Medicare, private insurance, or employer-sponsored insurance. This funding mechanism is estimated to generate an additional $\$ 200$ million in funding for PCORI in 2013. Beginning in 2014 and continuing through 2019, that fee increases to $\$ 2$ a person, which will mean that more than \$500 million will flow into the PCORI trust fund."

The passage of health reform was not without its challenges, some of which called into question its constitutional legality. On June 28, 2012, the U.S. Supreme Court upheld the ACA, in a mixed decision. There had been much speculation over the individual mandate, with the court ruling that it was a constitutional exercise of Congress' power to levy taxes. Also of note, the court held that forcing states to expand Medicaid was unconstitutional. The federal government cannot cut off existing Medicaid funding to states that choose not to proceed with expansion. The net result of the decision was that it cleared the way for a more rapid implementation of the ACA.

Even though the ACA was prominently featured during the campaign debates for Congress and the presidency, the election outcome will not likely have any significant impact on the reforms of the ACA. The proverbial train has left the station and is flying down the track. But what does that mean for us in our everyday practice?

\section{Quality Reporting Measures Through CMS}

The question can best be answered by first focusing on the definition and evolution of quality of care in the United States. In 2001, the Institute of Medicine defined quality as that which is safe, effective, efficient, equitable, timely, and patient-centered.
Over the last several years, these 6 domains have evolved and have subsequently become embodied into a national quality strategy that frames quality by 3 specific aims: better care, affordable care, and healthy people/healthy communities.

Health reform has set the stage for funding the development of new quality measures that will ultimately be used in current and soon-to-be-expanded quality reporting and valuebased purchasing initiatives. Moreover, such measures would serve as the substrate for innovative payment and delivery models such as accountable care organizations and patientcentered medical homes. Although quality measurement and reporting activities are not new activities, as noted by the launch of the hospital-based inpatient quality reporting program in 2006, the depth and breadth of its expansion into various settings of care such as psychiatric hospitals and long-term-care facilities post health reform is new (Fig. 1).

However, application in nuclear medicine and molecular imaging has been limited largely by the lack of consensus around what defines quality. In this current environment, is it sufficient to focus on the quality of the image as the metric to determine the value of the procedure in improving patient care, or are more specific metrics needed to make such a claim? As such, its unique definition necessitates a deeper look into how health reform and its focus on measurement and reporting will affect the profession. Most notably, the areas of interest lie in quality measures and appropriate-use criteria. However, ongoing parallel issues in accreditation and certification remain, as well as those focused on safety and radiation exposure.

In the hospital setting, the hospital inpatient quality reporting program forms the foundation of the hospital inpatient value-based purchasing program beginning fiscal year 2013 and is designed to link payment to quality processes, outcomes, and efficiency. The program is funded by a payment reduction that is applied across most hospitals. The payment reduction will be $1 \%$ in fiscal year 2013 and will increase every year by $0.25 \%$ until reaching $2 \%$. The hospitals, in turn, have the opportunity to earn a value-based incentive payment based on achievement or improvement on a defined set of quality metrics.

The quality measures in the program are mandated by the ACA to come from the hospital inpatient quality reporting program. All measures must be publicly reported on the Hospital Compare Web site for $1 \mathrm{y}$ before they are eligible for inclusion in the hospital inpatient value-based purchasing program.

The first year of the program focuses on clinical processes of care and patient experience of care. Outcome measures will be introduced beginning fiscal year 2014, and an efficiency measure that assesses Medicare spending per beneficiary will be introduced afterward. The Centers for Medicare and Medicaid Services (CMS) will publicly report hospital scores on all measures through the Hospital Compare Web site. Although this is a tremendous step toward improving the quality of inpatient care, what relevance does this have for our profession? We need to turn to the hospital outpatient setting to begin to see how imaging may be impacted by health reform. 
The hospital outpatient quality reporting program, modeled after the hospital inpatient quality reporting program, is a quality data reporting program implemented by CMS for outpatient hospital services. Currently there are 6 imaging efficiency measures included in the hospital outpatient quality reporting program; one additional measure will be added for the 2014 payment determination (11). Table 2 presents these measures.

Moving into the office setting and focusing on the physician more specifically, what has been the impact of health reform? Since 2007, physicians have been tasked to collect and report quality measure data for CMS through the Physician Quality Reporting System (PQRS) incentive program. As a part of this program, physicians must report on a specified minimum number of measures based on the reporting mechanism and reporting year. Over the last $5 \mathrm{y}$, PQRS has undergone many changes as it continues to evolve and includes well over 200 quality measures in the 2012 program across multiple therapeutic areas.

Individual eligible professionals meet the criteria for satisfactory submission of PQRS quality-measures data via one of several reporting mechanisms. Medicare Part B claims, a qualified PQRS registry, a qualified electronic health record (EHR) product, or a qualified PQRS data submission vendor for services furnished during a 2012 reporting period will qualify professionals to earn a PQRS incentive payment equal to $0.5 \%$ of their total estimated charges allowed under the Medicare Part B physician fee schedule for covered professional services furnished during that same reporting period. However, beginning in 2015, physicians will face a penalty. Also starting in 2015, CMS will implement the physician value-based payment modifier, also known as the VBPM, for groups of 100 or more providers. This modifier will be based on participation in PQRS, performance on quality measures reported through the PQRS, and cost measures that have been specified in the final rule for the 2013 Medicare Part B physician fee schedule. The VBPM will apply to Medicare-paid amounts

TABLE 2

2012-2013 Imaging Efficiency Measures (11)

\begin{tabular}{ll}
\hline \multicolumn{1}{c}{2012} & 2013 \\
\hline $\begin{array}{l}\text { OP-8: MRI lumbar } \\
\text { spine for low }\end{array}$ & $\begin{array}{c}\text { OP-15: use of brain CT in the } \\
\text { emergency department for } \\
\text { back pain }\end{array}$ \\
$\begin{array}{l}\text { OP-9: mammography } \\
\text { follow-up rates }\end{array}$ \\
$\begin{array}{l}\text { OP-10: abdominal CT } \\
\text { use of contrast material }\end{array}$ \\
OP-11: thoracic CT use \\
of contrast material \\
OP-13: cardiac imaging \\
for preoperative risk \\
assessment for noncardiac \\
low-risk surgery \\
OP-14: simultaneous use of \\
brain CT and sinus CT
\end{tabular}

for beneficiary services under the Medicare Part B physician fee schedule. Starting in 2017, the payment modifier will apply to all providers regardless of specialty or whether they are individual providers.

Specialty societies, including the Society of Nuclear Medicine and Molecular Imaging (SNMMI), have begun to provide tools and services to their members to facilitate PQRS participation. To that end, SNMMI has partnered with CECity to create an online tool to support nuclear medicine physicians that was recently made available to its membership. As stipulated in the 2013 final rule for the Medicare Part B physician fee schedule, quality measures available for use in pay-for-reporting and value-based purchasing for 2013 and 2014 are outlined. Of note are 5 new measures, developed jointly by the American College of Radiology and the American Medical Association Physician Consortium for Performance Improvement, that focus on radiation dose optimization. These measures, which will be available for reporting in 2014, attempt to improve outcomes for patients by reducing ionizing radiation necessary to perform an imaging study while preserving the highest diagnostic image quality. Quality measures that could be used by nuclear medicine physicians include those presented in Table 3.

\section{Appropriate-Use Criteria}

More than a decade ago, use statistics showed diagnostic imaging to have the fastest growth among all medical services covered by Medicare. Health plans, health policy makers, and other stakeholders continue to look for approaches to manage growth in imaging costs and limit unnecessary patient exposure to radiation. Appropriate-use criteria may fit this bill.

As noted by the American College of Cardiology, "[appropriate-use criteria] are intended to define 'when' and 'how often' to perform a given procedure in the context of scientific evidence, the health-care environment, the patient's profile and a physician's judgment." (5). Although the criteria can help inform individual patient care decisions, they are best used to evaluate patterns of care by physicians over time. It is anticipated that appropriate-use criteria are more likely to shape delivery of imaging services within hospitals and other settings than pay for performance and pay for reporting. Further, it is fully anticipated that appropriate-use criteria will be incorporated in hospital clinical decision support systems rather than in performance-based payment systems $(6,7)$. This implementation will most likely be in the form of popups on the screen when a physician tries to order an examination and will serve as a mechanism to support ongoing provider education.

SNMMI has recently been awarded a \$300,000 grant from the Agency for Healthcare Research and Quality to develop novel dissemination platforms and applications using electronic media, video and Internet mechanisms, and multiple interactive technologies to engage oncology providers who are most likely to order advanced diagnostic imaging tests during their treatment of patients. Such devel- 
TABLE 3

Finalized PQRS Individual Quality Measures Relevant for Nuclear Medicine Physicians Available for Reporting for 2013 and 2014 (12)

\begin{tabular}{|c|c|}
\hline PQRS no. & Measure \\
\hline \multicolumn{2}{|l|}{$\begin{array}{l}2013 \\
\quad \text { reporting }\end{array}$} \\
\hline 10 & Stroke and stroke rehabilitation: $\mathrm{CT}$ or MR imaging reports \\
\hline 21 & Perioperative care: venous thromboembolism prophylaxis (when indicated in all patients) \\
\hline 24 & $\begin{array}{l}\text { Osteoporosis: communication with physician managing ongoing care after hip, spine, or distal radius for men } \\
\text { and women aged } 50 \text { y and over }\end{array}$ \\
\hline 40 & Osteoporosis: management after hip, spine or distal radius for men and women aged $50 \mathrm{y}$ and over \\
\hline 76 & Prevention of catheter-related bloodstream infections: central venous catheter insertion protocol \\
\hline 145 & Radiology: exposure time reported for procedures using fluoroscopy \\
\hline 146 & Radiology: inappropriate use of "probably benign" assessment category in mammography screening \\
\hline 147 & Nuclear medicine: correlation with existing imaging studies for all patients undergoing bone scintigraphy \\
\hline 195 & Radiology: stenosis measurement in carotid imaging studies \\
\hline 225 & Radiology: reminder system for mammograms \\
\hline TBD & Cardiac stress imaging not meeting appropriate-use criteria: preoperative evaluation in low-risk surgery patients \\
\hline TBD & Cardiac stress imaging not meeting appropriate-use criteria: routine testing after percutaneous coronary intervention \\
\hline TBD & Cardiac stress imaging not meeting appropriate-use criteria: testing in asymptomatic, low-risk patients \\
\hline \multicolumn{2}{|r|}{$\begin{array}{l}2014 \\
\quad \text { reporting }\end{array}$} \\
\hline TBD & Radiation dose optimization: use of a standardized nomenclature for CT imaging description \\
\hline TBD & $\begin{array}{l}\text { Radiation dose optimization: cumulative count of potential high-dose-radiation imaging studies: CT scans and cardiac } \\
\text { nuclear medicine scans }\end{array}$ \\
\hline TBD & Radiation dose optimization: reporting to a radiation dose index registry \\
\hline TBD & Radiation dose optimization: images available for patient follow-up and comparison purposes \\
\hline TBD & Radiation dose optimization: search for prior imaging studies through a secure, authorized, media-free shared archive \\
\hline
\end{tabular}

$\mathrm{TBD}=$ to be determined

opments will further educate providers as to which patients would most benefit from this technology.

Since the spring of 2012, SNMMI has worked with the Alzheimer's Association to develop a set of appropriate-use criteria for $\beta$-amyloid imaging. The issue of the role of imaging in dementia remains unclear to many physicians, and with the advent of new radiopharmaceutical agents the opportunity for the profession to take a leadership role to define the appropriate patient and clinical scenario has become imminent. To enhance ultimate adoption of criteria, the development of appropriate-use criteria requires crossspecialty cooperation and involvement. The current process has included both dementia and imaging experts charged with systematically reviewing available evidence and participating in consensus-building discussions to draft the final recommendations. As with guidelines and performance measures, gaining provider acceptability about the science undergirding the recommendations is only the first step in adoption and ultimate improvements in the quality of care. Other steps are required to ensure attainment of the ultimate goal. To that end, there are several ongoing initiatives to incorporate appropriate-use criteria, in general, into the workflow, a necessity to support full provider adoption. The American Board of Internal Medicine Foundation's Choosing Wisely (8) initiative identifies specific tests and procedures "whose necessity should be questioned and discussed" to help physicians be better stewards of finite health care resources." More than 30 specialty societies have supported this initiative, including SNMMI. Several of the programs address nuclear imaging, including how and when to perform radionuclide stress cardiac imaging as a preoperative assessment in patients scheduled to undergo low-risk noncardiac surgery.

\section{WHAT IS NEW IN 2013 AND BEYOND?}

Some critics of the new health reform law contend that the Congressional Budget Office cost estimate understates the law's true cost because the law does not fix Medicare's flawed sustainable-growth-rate payment formula for physicians. Because Congress is certain to enact a fix, these critics contend, its cost should have been part of the health reform law. However, the cost of fixing the sustainable-growth-rate formula would exist with or without the new law. In December 2009, Congressional Budget Office projected the cost of bill 3961 of the House of Representatives, the Medicare Physician Payment Reform Act, at $\$ 210$ billion from 2010 to 2019. By June 2011, 18 mo later, the projected cost for eliminating the formula had increased to nearly $\$ 300$ billion. It is estimated that further delaying a permanent sustainable growth rate solution will further increase the estimated cost and make the formula's elimination that much more difficult. If Congress were to wait until 2016 to do away with the sustainable growth rate, the estimated combined cost for providing temporary patches through 2016 and then eliminating the sustainable growth rate approaches $\$ 600$ billion (9). 
The new law builds on the Health Information Technology Act of 2009, which was part of the American Recovery and Reinvestment Act of 2009. ACA and the Health Information Technology Act of 2009 are mutually supportive; each promotes and advances health information technology. For example, ACA requires accountable care organizations to use technology, including telehealth (delivery of health-related services and information via telecommunications technologies) and remote patient monitoring. It establishes health information technology protocols and standards for certain administrative functions. It also creates a time frame for public and private health plans to collaborate to simplify health insurance administration by developing common methods for claims processing, credentialing, and utilization review.

At the same time, there have been significant changes to the regulations for EHR (10). In a continued push to support EHR adoption and the promotion of nationwide health information exchange to improve health care in the United States, on August 23, 2012, CMS and the Office of the National Coordinator for Health Information Technology issued final rules for the second of a 3-part EHR incentive program. Table 4 presents a description of the initiative. CMS' latest rule finalizes the core and menu structure for meaningful use objectives and the clinical quality measures for stage 2 of the EHR incentive program as well as Medicare's payment adjustments for eligible providers who fail to demonstrate meaningful use. More specifically, those who do not demonstrate meaningful use of EHR systems by October 1, 2014, will be subject to a $1 \%$ penalty from Medicare. Of relevance to the radiology community is that CMS has finalized 4 categories of hardship exceptions, inclusive of this specialty area, for eligible professionals. However, the exception has a mandated 5-y limitation. CMS has subsequently committed itself to identifying ways for physicians who meet this hardship to adopt EHRs as new technology emerges.

In this new world of quality, evidence, and value, it will become even more important for nuclear medicine providers and molecular imagers to evaluate the appropriateness of conducting studies in every patient. Although there may not be performance measures per se, there undoubtedly will be a set of appropriate-use criteria available by which you may be held accountable.

For professional societies, the challenge will be to work with their members to gather the evidence necessary to meet the requirement for all these new mandates and quality processes. In addition they will need to continue to advocate for the development and use of clinically relevant measures and criteria that will truly enhance patient outcomes. Furthermore, it will be incumbent on professional societies to continue to educate and train their membership around the knowledge and implementation of these metrics of quality, as it has become evident that enhancing quality and value is a cornerstone to reforming our nation's health.

\section{DISCLOSURE}

No potential conflict of interest relevant to this article was reported.
TABLE 4

Meaningful Use and the Adoption of Health Information Technology (13)

\begin{tabular}{ll}
\hline $\begin{array}{c}\text { Meaningful-use } \\
\text { stage }\end{array}$ & \multicolumn{1}{c}{ Description } \\
\hline 1 & $\begin{array}{c}\text { Capturing electronic health } \\
\text { information and using those } \\
\text { data to track and communicate } \\
\text { clinical conditions } \\
\text { Increased focus on health } \\
\text { information exchange; } \\
\text { mobilization of electronic } \\
\text { health information across } \\
\text { organizations within a } \\
\text { region, community, or health } \\
\text { system; electronic orders } \\
\text { and results } \\
\text { Emphasis on quality, safety, } \\
\text { and efficiency; promotion of } \\
\text { decision support systems and } \\
\text { patient access to self-management } \\
\text { tools }\end{array}$ \\
\hline 3 & \\
\hline
\end{tabular}

\section{REFERENCES}

1. Fisher ES, Bynum JP, Skinner JS. Slowing the growth of health care costs: lessons from regional variation. N Engl J Med. 2009;360:849-852.

2. Squires D. Explaining High Health Care Spending in the United States: An International Comparison of Supply, Utilization, Prices, and Quality. New York, NY: Commonwealth Fund; May 2012.

3. Schoen C, Davis K, How SK, Schoenbaum SCUS. Health system performance: a national scorecard. Health Aff (Millwood). 2006;25:w457-w475.

4. Jamoom E, Beatty P, Bercovitz A, et al. Physician Adoption of Electronic Health Record Systems: United States, 2011. Hyattsville, MD: National Center for Health Statistics; 2012. NCHS data brief 98 .

5. Patel MR, Spertus JA, Brindis RG, et al. ACCF proposed method for evaluating the appropriateness of cardiovascular imaging. J Am Coll Cardiol. 2005;46: 1606-1613.

6. Hernandez MB, Salguero PB, DeMuth KE, et al. Improving both service outcome and volume using EMR and guidelines (SPECT appropriateness criteria): the MORE trial. In: The 17th Annual Scientific Session of the American Society of Nuclear Cardiology: Final Program. Bethesda, MD: American Society of Nuclear Cardiology; 2012:16.

7. Solberg LI, Wei F, Butler J, Palattao K, Vinz C, Marshall M. Effects of electronic decision support on high-tech diagnostic imaging orders and patients. Am J Manag Care. 2010;16:102-106.

8. Choosing wisely. The ABIM Foundation Web site. http://www.abimfoundation. org/Initiatives/Choosing-Wisely.aspx. Accessed January 25, 2013.

9. American Medical Association, Economic and Health Policy Research, June 2011, based on "Medicare's Payments to Physicians: The Budgetary Impact of Alternative Policies," Congressional Budget Office, June 14, 2011, and AMA Economic and Health Policy Research estimates.

10. EHR incentive programs. CMS.gov Web site. http://www.cms.gov/Regulationsand-Guidance/Legislation/EHRIncentivePrograms/index.html?redirect =/ ehrincentiveprograms/. Accessed January 25, 2013.

11. Hospital outpatient regulations and notices. CMS.gov Web site. http://cms. hhs.gov/Medicare/Medicare-Fee-for-Service-Payment/HospitalOutpatientPPS/ Hospital-Outpatient-Regulations-and-Notices.html. Accessed January 25, 2013.

12. Medicare program: revisions to payment policies under the physician fee schedule, DME face-to-face encounters, elimination of the requirement for termination of non-random prepayment complex medical review and other revisions to Part B for CY 2013-final rule with comment period. Fed Regist. 2012;77: 68891-69373.

13. An introduction to the Medicaid EHR incentive program for eligible professionals. CMS.gov Web site. http://www.cms.gov/Regulations-and-Guidance/Legislation/ EHRIncentivePrograms/Downloads/Medicaid-EHR-Guide.pdf. Accessed February $6,2013$. 